\title{
Biopsy guided by dermoscopy in cutaneous pigmented lesion - Case report
}

\author{
Biópsia cutânea de lesão pigmentada guiada pela dermatoscopia - Relato de caso
}

\author{
Lislaine Bomm ${ }^{1}$ \\ Juan Manuel Piñeiro Maceira ${ }^{3}$ \\ Maria de Fatima Guimarães Scotelaro5
}

\author{
Marcela Duarte Villela Benez ${ }^{2}$ \\ Isabel Cristina Brasil Succi ${ }^{4}$
}

\begin{abstract}
It may be clinically difficult to differentiate early-stage melanoma from benign tumors, specially pigmented seborrheic keratosis. Dermoscopy can help; however, the findings are not always conclusive. Therefore, histopathology may be necessary for a correct diagnosis. We describe a melanocytic lesion with dubious clinic and dermoscopic findings. An incisional biopsy of a suspicious area, guided by dermoscopy, was performed to clarify the findings.

Keywords: Biopsy; Dermoscopy; Keratosis, Melanoma; Seborrheic

Resumo: A diferença clínica entre melanoma inicial e tumores benignos pode ser difícil em algumas ocasiões, especialmente na ceratose seborreica pigmentada. A dermatoscopia pode ajudar; porém, os achados nem sempre são conclusivos, de modo que a histopatologia pode ser necessária para o diagnóstico correto. Descrevemos uma lesão melanocítica com aspectos clínicos e dermatoscópicos duvidosos. Nesse caso, a biópsia incisional de área suspeita, guiada pela dermatoscopia, estabeleceu o diagnóstico.

Palavras-chave: Biópsia; Ceratose seborreica; Dermoscopia; Melanoma
\end{abstract}

\section{INTRODUCTION}

Dermoscopy or epiluminescence microscopy, noninvasive and practical, is nowadays an important tool for the diagnosis of pigmented lesions, helping to differentiate non-melanocytic lesions from melanocytic ones, as well as to distinguish between benign and malignant melanocytic lesions. In some situations, however, there are difficulties in the interpretation of dermoscopic signs, because of mixed characteristics and the subjective analysis of the method. If melanoma persists as a diagnostic possibility, an incisional biopsy should be performed in the dermoscopically suspicious area. ${ }^{1,2,3}$

\section{CASE REPORT}

A 50-year-old white male physician, born and raised in Rio de Janeiro, was referred to our

Received on 19.12.2011.

Approved by the Advisory Board and accepted for publication on 16.10.2012.

* Work conducted at Pedro Ernesto University Hospital (Hospital Universitário Pedro Ernesto) - Rio de Janeiro State University (Universidade do Estado do Rio de Janeiro - HUPE-UERJ) - Rio de Janeiro (RJ), Brazil.

Conflict of interest: None

Financial funding: None

Physician - Resident in Dermatology at Pedro Ernesto University Hospital (Hospital Universitário Pedro Ernesto) - Rio de Janeiro State University (Universidade do Estado do Rio de Janeiro - HUPE/UERJ) - Rio de Janeiro (RJ), Brazil.

Adjunct Dermatologist at the Outpatient Clinic of Dermatologic Surgery and Outpatient Clinic of Dermoscopy, Pedro Ernesto University Hospital - Rio de Janeiro State University (HUPE/UERJ) - Rio de Janeiro (RJ), Brazil.

Postdoctorate in Dermatopathology from the Armed Forces Institute of Pathology - Associate Professor at the Department of Pathology - Federal University of Rio de Janeiro (Universidade Federal do Rio de Janeiro - UFRJ) and Professor at Pedro Ernesto University Hospital - Rio de Janeiro State University (HUPE/UERJ) - Rio de Janeiro (RJ), Brazil.

Professor at Pedro Ernesto University Hospital - Rio de Janeiro State University (HUPE/UERJ) - Rio de Janeiro (RJ), Brazil.

PhD in Dermatology from the Federal University of Rio de Janeiro (UFRJ) - Professor at the Dermatology Service, Rio de Janeiro State University (HUPE/UERJ) - Rio de Janeiro (RJ), Brazil.

C 2013 by Anais Brasileiros de Dermatologia 
Dermatology Department for skin cancer screening. On physical examination, we observed a $3 \mathrm{~cm}$ blackened macula with an irregular border and more than one color on the right calf (Figure 1). The patient told us that the lesion had appeared 10 years ago, showing progressive growth in recent months. He had a positive family history of melanoma. Dermoscopic examination showed a peripheral atypical pigmented network structure (more marked on the right of the lesion), brownish streaks in the central area and in the right periphery, a peripheral area with a black blotch and some globular structures, an amorphous area with a pseudofollicular opening and pseudocysts on the left of the lesion, beyond the veil in the center of the lesion (Figures 2 e 3).

As the lesion had some clinical aspects of seborrheic keratosis and the more suspicious dermoscopic findings were restricted to only a part of the lesion, we chose to perform an incisional biopsy (punch 4) in this area (with streaks). Histological examination showed confluent atypical melanocytes, occupying part of the epidermis and extending into the superficial dermis, several mitotic figures, and an inflammatory reaction in the dermis. A diagnosis of superficial spreading melanoma was rendered (Breslow thickness $=0.37 \mathrm{~mm}$ ) (Figure 4).

The lesion was then removed with a $1 \mathrm{~cm}$ margin, and the wound was left to heal by secondary intention. The histological examination of this surgical specimen just showed a residual inflammatory reaction. There were no other melanoma features. The area of the blotch seen on the dermoscopy was histologically related to acanthosis, papilomatosis, and extensive deposition of melanin pigment in the dermis (consistent with partial regression phenome-

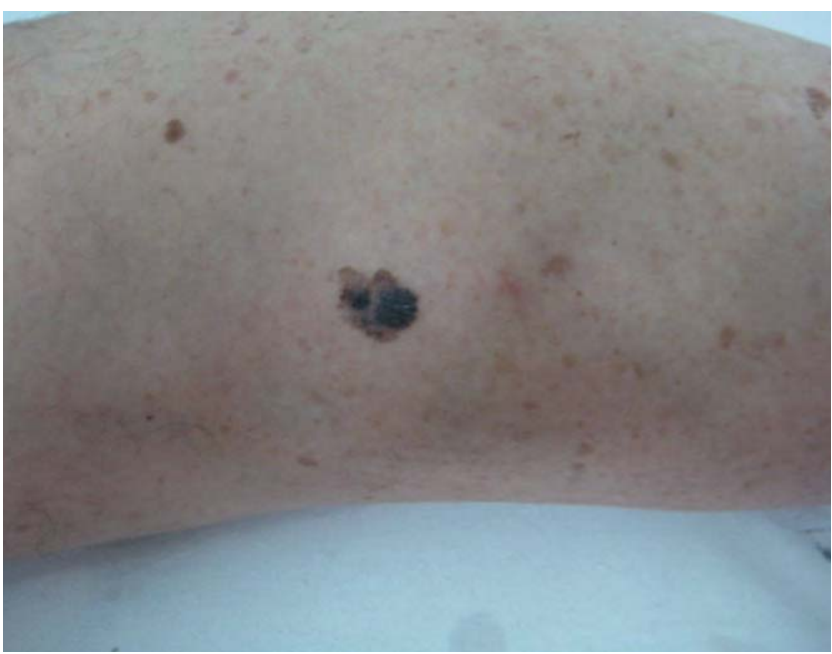

FIGURE 1: Multi-colored blackened macula on the right calf with an irregular border

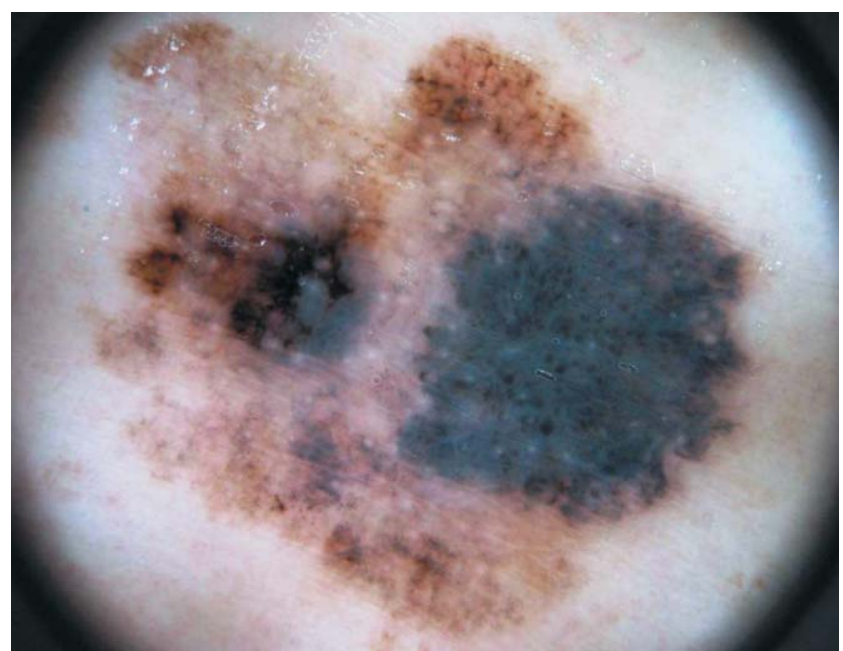

FIGURE 2: Peripheral atypical pigmented network structure (more marked on the right of the lesion), brownish streaks in the central area and right periphery, a peripheral area with a black blotch and some globular structures, an amorphous area with a pseudofollicular opening and pseudocysts on the left of the lesion, beyond the veil in the center of the lesion

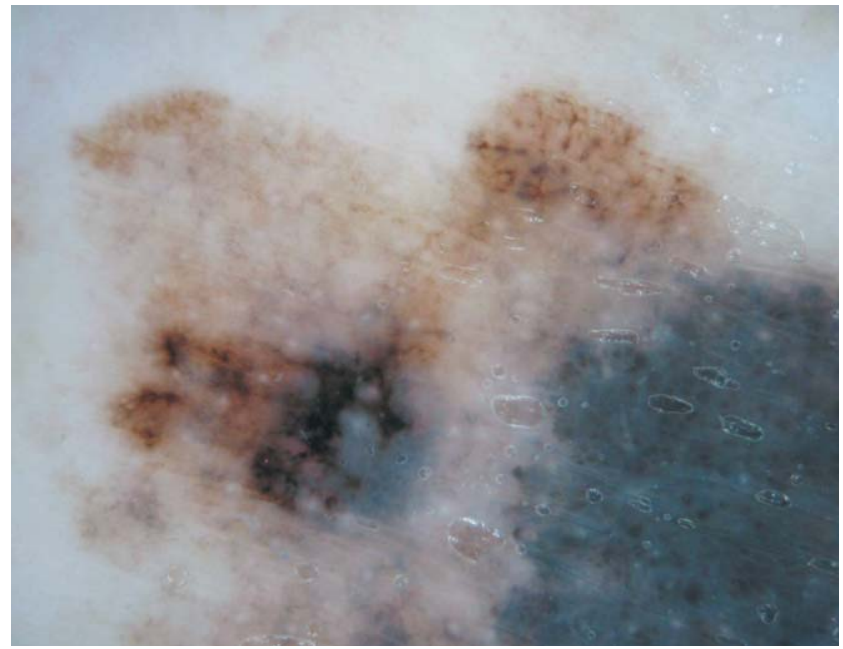

FIGURE 3: Details of the suspicious area biopsied

non) (Figure 5). Thus, we found that the portion of the malignant lesion had been excised with incisional biopsy guided by dermoscopy.

\section{DISCUSSION}

Melanoma with seborrheic keratosis (SK)-like features is a potential diagnostic pitfall, since it may present with classic dermoscopic features of SK, including multiple comedo-like openings and milia-like cysts, which may prove to be misleading. ${ }^{1,2}$ SK usually presents an easy clinical diagnosis that does not require dermoscopic evaluation. However, if the clinician feels inclined to use dermoscopy to assess a SK-like lesion, it probably deserves careful and meticulous 


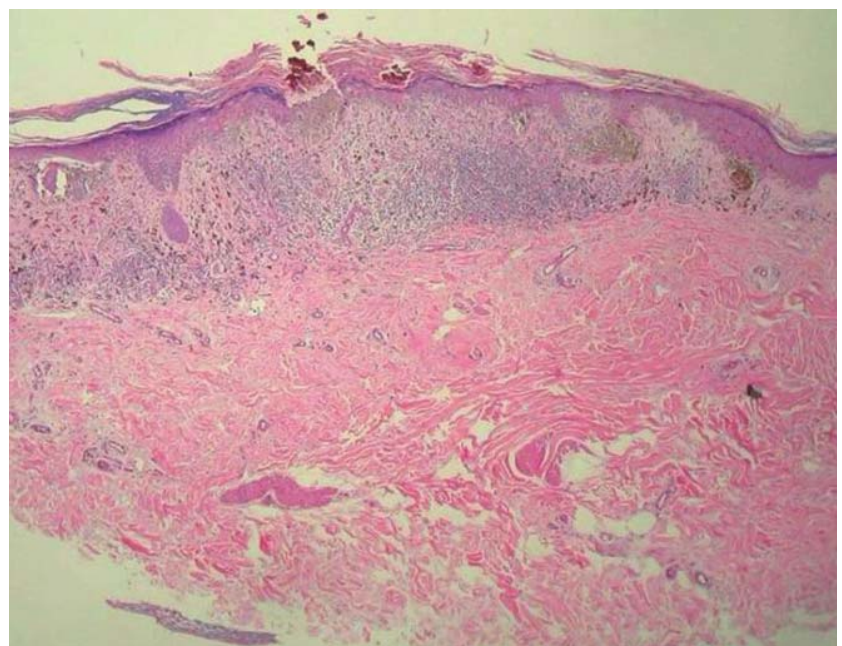

FIGURE 4: Dermoscopy-guided incisional biopsy revealing a 0.37 mm-thick melanoma (panoramic view, x40, hematoxylin-eosin) scrutiny to rule out features of melanoma., ${ }^{3,45}$ This is what occurred in the case reported, in which dermoscopy was fundamental in selecting the biopsy site.

Most retrospective and prospective studies do not show an influence on patient outcome after incisional biopsies in melanoma lesions. Although complete excisional biopsies are generally the recommended standard for melanoma surgery, incisional biopsies are currently recommended for histopathologic diagnosis of the most clinically or dermoscopically atypical portion of the lesion in certain circumstances, such as facial or acral location, low clinical suspicion or uncertainty of diagnosis, or very large lesions. ${ }^{6,78}$ Our patient's lesion showed suspicious dermoscopic aspects in a restricted area, so we opted for an incisional biopsy of that area, which proved diagnostic. An

\section{REFERENCES}

1. Braga JC, Scope A, Klaz I, Mecca P, Spencer P, Marghoob AA. Melanoma mimicking seborrheic keratosis: an error of perception precluding correct dermoscopic diagnosis. JAmAcadDermatol. 2008;58:875-80.

2. Carrera C, Segura S, Palou J, Puig S, Segura J,Marti RM, et al. Seborrheic keratosislike melanoma with folliculotropism. ArchDermatol. 2007;143:373-6

3. Lopes OS, Egito EP. Dermatologia comparativa: dermatoscopia em melanoma cutâneo. An Bras Dermatol. 2008;83:473-5

4. Aoyagi S, Hata H, Izumi K, litani MM , Shimizu H. Diagnostic pitfalls of using dermoscopic features to differentiate between malignant melanoma. ActaDermVenereol, 2010;90:440-1.

5. Rosendahl C, Tschandl P, Cameron A, Kittler H. Diagnostic accuracy of dermatoscopy for melanocytic and nonmelanocytic pigmented lesions. J Am AcadDermatol. 2011;64:1068-73.

6. Tran KL, Wright NA, Cockerell CJ. Biopsy of the pigmented lesion. When and how. J Am AcadDermatol. 2008;59:852-71.

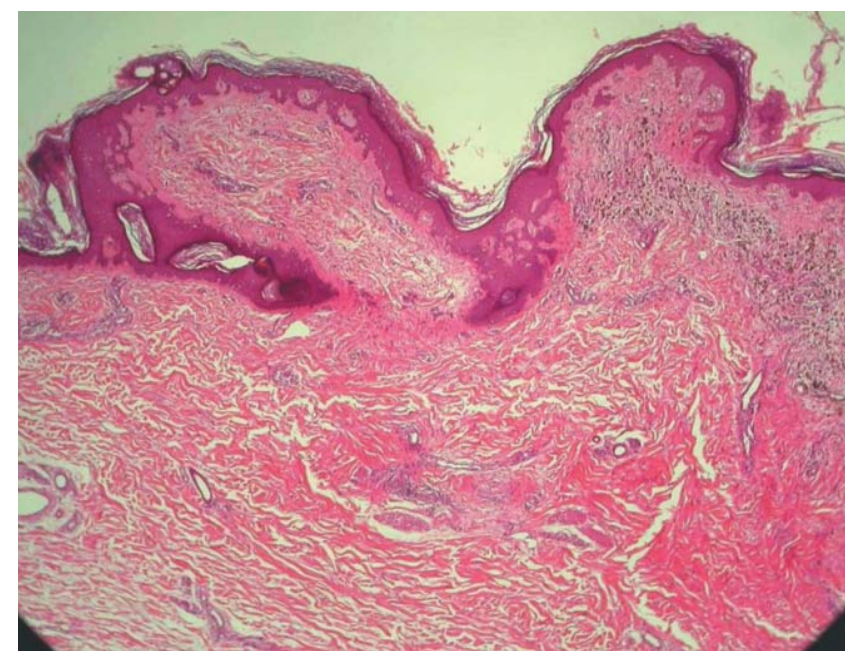

FIGURE 5: Excisional biopsy; the area of the blotch seen on dermoscopy was histologically related to acanthosis, papilomatosis, and extensive deposition of melanin pigment in the dermis (consistent with partial regression phenomenon)

excisional biopsy showed that the melanoma had been removed with the incisional biopsy of the suspicious area, since the remainder of the skin sample showed fibrosis only, representing perhaps the amorphous area and veil seen on dermoscopy.

Another important point to note in this case is that, even though the patient was a medical doctor and had a positive family history of melanoma, he was unable to recognize his leg lesion as worrisome.

This case illustrates that the judicious use of dermoscopy is very helpful in doubtful clinical cases of melanocytic/pigmented lesions. It also stresses the need for more effective instruction of the general medical population in recognizing the "warning signs" of these cutaneous lesions in themselves and in their patients.

7. Bong JL, Herd RM, Hunter JA. Incisional biopsy and melanoma prognosis. J Am AcadDermatol. 2001;46:690-4.

8. Bichakjian CK, Halpern AC, Johnson TM, Foote Hood A, Grichnik JM, Swetter SM et al. Guidelines of care for the management of primary cutaneous melanoma. J AmAcadDermatol. 2011;65:1032-44.

\author{
MAILING ADDRESS: \\ Lislaine Bomm \\ Boulevard 28 de setembro, 77 \\ Vila Isabel \\ 20.551-030 Rio de Janeiro, RJ. \\ lislainebomm@gmail.com
}

How to cite this article: Bomm L, Benez MDV, Maceira JMP, Succi ICB, Scotelaro MFG. Biopsy guided by dermoscopy in cutaneous pigmented lesion - Case report. An Bras Dermatol. 2013;88(1):125-7. 